\title{
The contribution of research-based master's theses to knowledge building in nursing
}

\author{
Ragnhild Helles $\varnothing^{*}$, May Solveig Fagermoen \\ Department of Nursing Science, Institute of Health and Society, Faculty of Medicine, University of Oslo, Oslo, Norway
}

Received: February 8, 2018

DOI: $10.5430 /$ jnep.v8n $11 \mathrm{p} 35$
Accepted: May 30, 2018

Online Published: June 22, 2018

\begin{abstract}
Purpose: The purpose was to investigate the topics and method applied in research-based master's theses in nursing science. Methods: A total of 694 research-based master's theses produced in a period of 30 years representing the entire period of a university programme in nursing science were examined. We used an explorative design with a deductive-inductive approach. Results: The master's theses covered a variety of topics, ranging from basic theoretical and methodological issues to topics in clinical research, education and leadership. Four main themes were addressed: patient studies, practice studies, nursing education, and nursing management and leadership. Qualitative methods using interviews and some observations were the preferred approach. For those who used quantitative methods, surveys and a few quasi-experiments were identified. Nurses' responsibility for providing high-quality and safe care is a fundamental issue in nursing science. When great changes in health care alter the conditions for reaching this aim, we identified that master's students want to investigate the consequences for patients and nursing care. The fact that few students addressed education and leadership is worrying. It might affect the quality of education. Furthermore, one may question how nurses can be visionary and take a leading role, which is stated to be important in the literature, in developing future health and nursing care.

Conclusions: Our study uncovered the importance of investigating research-based master's theses because it provides a basis for reflection on topics that need to be emphasised in the future.
\end{abstract}

Key Words: Nursing science, Master programme, Research-based master's theses, Knowledge building in nursing

\section{INTRODUCTION}

One characteristic of scientific and practical disciplines is systematic knowledge building of their subject matter. Publications on the development of nursing science in nursing practice, education and management and specific phenomena in patients and/or nurses are numerous. Examining master's nursing education and programmes is regarded as important for analysing how education meets societal needs. ${ }^{[1]}$ This is in line with the Institute of Medicine, which states that nursing education needs to be transformed to meet future challenges. ${ }^{[2]}$ Gerard et al. ${ }^{[1]}$ emphasise that societal drivers for change need to be accounted for in the education of nurses at master's level. They state that analysing what the education has addressed in the past provides us a basis for identifying the paths for the future. For example, they identify that nurses' accountability for achieving quality goals, new technology and inter-professional practice need to be the future framework. In addition, where health care takes place is in transformation, and these changes should be considered. ${ }^{[3]}$ However, analysis of the substance of masters' theses over years to identify master's students' knowledge contribution are rarely identified and discussed in the literature. Searching

\footnotetext{
*Correspondence: Ragnhild Hellesø; Email: ragnhild.helleso@medisin.uio.no; Address: Department of Nursing Science, Institute of Health and Society, Faculty of Medicine, University of Oslo, Oslo, Norway.
} 
in CINAHL, Google Scholars and selected journals using the words nurse, nurses, nursing and/combined with master, thesis and dissertations, previous studies addressed the evaluation of nurse education at bachelor's, master's and $\mathrm{PhD}$ levels. Only a few studies were identified that addressed the analysis of the substance of masters' theses. Gutierrez, Leite, Pagliuca \& Erdman ${ }^{[4]}$ analysed topics of master's theses and doctoral dissertations in Brazil, but only the abstract is available in English. A review of topics and methods in nursing research in Finland ${ }^{[5]}$ included licentiate (equal to master's theses) and doctoral dissertations. They reported that the majority of the topics emphasised clinical practice. Research on community health was reported to be increasingly prominent with one third addressing questions in that area. The use of a literature review, not empirical studies, was identified as the most frequent approach in master's theses. ${ }^{[6]}$

When the purpose of a study is to systematically examine the content of nursing knowledge development such as research topics, theses, or programmes of research, one needs to frame this in a nursing perspective. Agreement in the literature is limited to what the specific content should be. ${ }^{[7]}$ Over the years, scholars in nursing have searched for a way to define the specifics of nursing science. The discussion on the necessity of a theory or theories of nursing, however, really began with the seminal article on the discipline of nursing by Donaldson and Crowley. ${ }^{[8]}$ In this paper, they argued that nursing, like other disciplines, must be characterised by a unique perspective, identified boundaries and a coherent body of knowledge.

In 1967, a World Health Organisation Expert Committee ${ }^{[9]}$ concluded that nursing research could be classified into three categories: clinical nursing, nursing leadership and nursing education. These categories were linked with the purpose of improving nursing education and practice. In 1996 the European Health Committee ${ }^{[10]}$ revised a former version and included nursing theory as a fourth category for nursing research. These elements operate within the clinical process in nursing with nurse and patient as interacting agents. Furthermore, research within the other categories must be linked to some core nursing elements to be considered as nursing research.

In Norway, the Norwegian School of Advanced Education in Nursing was established in 1925 . This was a private school responsible for educating nurse teachers and nurse leaders until the programme was transferred to the University of Oslo in 1985, where it is today organised as a department within the Faculty of Medicine. The purpose of this change was to provide an academic education for nurses to qualify for teaching and leadership positions and to contribute to the development of nursing science in general. All students in the master's programme at the University of Oslo are required to submit a research-based thesis at the end of their education.

\section{Aims}

The aim of the study was to investigate research-based master's theses in nursing science. In particular, we explored the content of the theses, to what extent the topics had changed during different educational programmes, and the design and methods applied.

\section{MATERIALS AND METHODS}

An explorative design using abstracts from master's theses was applied. All master's theses from 1985 to 2015, representing the entire period of the university programme in nursing science at the University of Oslo, were investigated.

The Department of Nursing Science (hereafter: "the Department") has offered two different lengths of programmes at master's level. Programmes from the first 20 years, from 1987 to 2005, were equivalent to three-year full-time studies (P1). Students could choose between two specialisations; education (qualifying for teaching nursing students at bachelor's level) and nursing leadership (qualifying for a position in a hospital or local authority health care). After changes in the educational system determined at national level, named the "Quality Reform for Higher Education", ${ }^{[11]}$ the Department has run a two-year full-time master's programme (P2). Thus, the change in the programme was not chosen by the nursing department. From 2005, the Department offered one programme in nursing science without specialisations, but since 2011, an additional programme in advanced geriatric nursing has been offered. Before 2005, the maximum length of the master's theses was 120 pages, while since 2005, the length has been 90 pages. The expectation for students to hold an acceptable scientific level did not change between the two programmes.

\subsection{Analysis}

Before starting the analysis, all abstracts were organised in tables chronologically by year of graduation with information about the topics and aims of the thesis. Year of graduation was of interest because of the different length of the programmes. Thereafter we identified and organised the chosen design, the methods used in data collection and analysis, the study setting, and characteristics of the sample. Finally, the results were organised into tables.

A deductive-inductive approach was applied to analyse the abstracts. ${ }^{[12]}$ In the deductive phase, Kim's typology of nursing science ${ }^{[13]}$ guided us, resulting in organisation of all 
abstracts into two main domains: Clinical Nursing Science and Professional Issues. In the next step, the inductive phase, a conventional content analysis was applied ${ }^{[14]}$ because it opens up for developing codes and categories. This chosen approach to our analysis gave us insight into a variety of topics as well as providing a coding scheme which was useful to determine eligible data and provided the final themes. To be able to investigate changes between the two programmes, we calculated the average number of master's theses the students had produced per year and per theme.

\subsection{Trustworthiness}

All abstracts were initially read by both authors with the aim of reaching a consensus of organising the theses into the main domains. Thereafter, each author coded all abstracts independently and the coding were compared. When disagreement occurred, which was rare, we discussed until agreement was reached.

\section{RESULTS}

A total of 694 master's theses were produced from 1987 to 2015. The analysis revealed four main themes: "patient studies", "practice studies", "nursing education" and "nursing management and leadership". The first three themes each had a variety of sub-themes. To give the reader an impression of the topics, we will illustrate these for each sub-theme. We also identified the methodological approaches used, which are presented after the main themes.

\subsection{Content and changes in the topics of master's theses} The first main theme, "patient studies", where patients or their next of kin were informants, were identified in 256
(36.7\%) of all the master's theses, respectively 174 during P1 and 82 during P2. These studies included two sub-themes: "problems related to illness" and "being a receiver of care", distributed as shown in Table 1. The mean number of studies submitted per year representing the two sub-themes showed that students have decreased their focus on patients' problems related to illness, while how patients experience being a receiver of care has increased from $\mathrm{P} 1$ to $\mathrm{P} 2$.

Problems related to illness reflected a variety of topics, such as stroke patients' loss and grief, cancer patients' physical problems related to nutrition, fatigue, vomiting and diarrhoea during treatment or their changed body image and selfimage. The pain experiences of patients admitted to intensive care units and elderly patients living in nursing homes were explored, showing that the phenomenon is independent of where they receive health care. The students mainly focused on the patients' experiences of their illness. A wide range of patients throughout different life courses responded about their experiences with being a receiver of care, i.e. their encounters with nursing care and health care services. In these studies, the students investigated assessments and patients' expectations. The students also addressed the experiences of being cared for of patients with a variety of illnesses, ranging from psychiatric problems to cancer, and parents of children with illness or disability. When students focused on the next of kin $(n=50)$, they were mainly concerned with how it was to be with their ill relative in the hospital and/or at home, and how to manage their own situation and feelings as family members. The students also addressed relatives' experiences of navigating in the health care system. We identified only one study where both patients and relatives were informants.

Table 1. Distribution of sub-categories of the theses within patient studies

\begin{tabular}{llll}
\hline & N (\%) & Mean per year P1 & Mean per year P2 \\
\hline Problems related to illness & $153(59.8)$ & 6.2 & 4.7 \\
Being a receiver of care & $103(40.2)$ & 3.1 & 4.4 \\
Total & $256(100)$ & 8.7 & 9.1 \\
\hline
\end{tabular}

In the second main theme, "practice studies", nurses and other health care providers were informants. The majority of master's theses addressed this theme $(n=274)$. The students addressed the following three sub-themes: "work context", "deliberations of nursing" and "enactments of care" (see Table 2). Here, students were concerned about many issues. Overall, the practice studies reflected conditions for ensuring safe and high-quality nursing.

In the sub-theme "work context", characteristics of the care organisation, colleagues and work environment were ad- dressed. For example, in some master's theses students investigated how work context influenced nurses' ability to care for patients as intended, implications of the case mix of the health care personnel for patient outcomes, and whether the primary nursing care model provided a better basis for documenting patient needs. We also identified master's theses that emphasised the basis for and possibilities of inter-disciplinary collaboration in home health care. As shown in Table 2, topics related to work context decreased from $\mathrm{P} 1$ to $\mathrm{P} 2$. 
The sub-theme "deliberations of nursing" was the most frequent topic and increased from P1 to P2. Many of the studies reflected nurses' deliberations on their ethical and professional responsibility for how they could perform best practice nursing and their deliberations on what nurses should focus on. In fact, these students were engaged in the essence of nursing by addressing nurses' experiences, knowledge and competency, and procedures and methods available in their practice. The informants were asked about a broad range of patient groups, such as caring for palliative patients at home, children with cancer, elderly patients, psychiatric care, pa- tients from different cultures and addicted persons. Some of the students highlighted existing challenges in practice and investigated how nurses reflected on these challenges. One example was their deliberations about relatives' presence in an intensive care unit, as a resource or a burden. Some students explored nurses' knowledge about classical nursing issues like ulcer pressure, hygiene, fall prevention and nutrition. We also found theses about how nurses could develop themselves as professionals, nurses' patterns of reading and updating themselves, and how to prevent burn-out among nurses.

Table 2. Distribution of sub-categories of the theses within practice studies

\begin{tabular}{llll}
\hline Sub-themes & N (\%) & Mean per year P1 & Mean per year P2 \\
\hline Work context & $74(27.0)$ & 3.2 & 1.1 \\
Deliberations of nursing & $138(50.4)$ & 2.3 & 6.5 \\
Enactments of care & $62(22.6)$ & 2.3 & 4.4 \\
Total & $274(100)$ & & \\
\hline
\end{tabular}

The number of studies within the third sub-theme "enactment of care" also increased from P1 to P2. This sub-theme reflects nurses' actions of care and interventions. In particular, students addressed patient education and nurse-patient interactions. Some examples illustrate the variety of topics: nurses and patients' relatives' communication with patients suffering from stroke, conversation and communication between persons with dementia and health care personnel in nursing homes, life stories as preventative interventions in nursing care, and the use of humour in dementia care. Other topics were collaboration between nurses and patients with suicidal thoughts, collaboration between parents and nurses in neonatal care, and negotiation in nursing practice as a strategy to empower patients.

The third theme "nursing education" was identified in 104 theses with three sub-themes as outlined in Table 3.

Table 3. Distribution of sub-categories of the theses within nursing education

\begin{tabular}{llll}
\hline Sub-themes & N (\%) & Mean per year P1 & Mean per year P2 \\
\hline Theories, ethics and values & $56(53.8)$ & 2.8 & 1.0 \\
Focus on teaching & $21(20.3)$ & 1.2 & 0 \\
Focus on learning & $27(25.9)$ & 1.0 & 1.0 \\
Total & $104(100)$ & & \\
\hline
\end{tabular}

Theory studies mainly covered ethics, values, philosophy of nursing, and history of nursing education. Examples were communication skills for nursing students, the place of empathy in nurse education, values in education, and proper professional nursing and competency. Data sources in these studies were mainly literature, while in the other studies, the respondents were teachers, supervisors and nursing students.

In the "focus on teaching", the master's theses mainly addressed content and methods in teaching and guidance for students' learning processes both in nursing school and in nursing practice. This involved the teachers' knowledge, competence and development as well as nurse supervisors' teaching experience in clinical settings. Other themes were methods for how to teach students communication, develop attitudes and learn in the practice setting. Data sources were mainly teachers and supervisors, students in only three studies, and literature in two cases. In P2, no students addressed these topics.

In "focus on learning", no changes between P1 and P2 occurred. Some studies addressed what the students learned in nursing school but more were concerned with their experiences and learning in the practice setting. These studies included students' information about their development of learning while giving nursing care in terms of tasks, attitudes 
and the importance of realising values in caring. Students' experience of stress and challenges in being close to patients' bodies and intimate parts were also reported. The students were the main respondents, in addition to some clinical supervisors and teachers.

The fourth main theme was "nursing management and leadership", represented by 60 (8\%) of the total number of theses, where 42 were written in $\mathrm{P} 1$. The students were engaged in nurse managers' responsibilities, how managers assess the need of nurse competencies, the impact of hospital organisation on nursing care, and tools for providing quality and safety for patients. Nurse managers from hospitals, public health, nursing homes and home health care were respondents in these studies.

\subsection{Design and methodological approaches}

The studies represented a variety of designs and methodological approaches. Some theses combined more than one method. We found that qualitative methods, using mainly interviews and some observations, were the preferred methods $(n=337)$. In 204 master's theses, quantitative methods were mostly surveys and to some extent quasi-experiments. In addition, 109 students had performed analyses of literature (books and articles) or conducted document analysis. For 44 theses, we were not able to identify the method applied. In Table 4, the methods for the two programmes for the four main themes are outlined. In the studies where more than one method was used, we counted all.

Table 4. Distribution of methods applied in the studies (mean per year)

\begin{tabular}{|c|c|c|c|c|c|}
\hline & Qualitative methods & Quantitative methods & Literature/Documents & Not available & Tota \\
\hline Patient studies P1 & $97(4.8)$ & $64(3.2)$ & $13(0.6)$ & 0 & 174 \\
\hline Patient studies P2 & $38(4.2)$ & $15(1.6)$ & $17(1.8)$ & $17(1.8)$ & 70 \\
\hline Practice studies P1 & $100(5)$ & $57(2.9)$ & $20(1)$ & 0 & 177 \\
\hline Practice studies P2 & $51(5.7)$ & $27(3)$ & $4(0.4)$ & $15(1.7)$ & 97 \\
\hline Education P1 & $25(1.25)$ & $20(1)$ & $44(2.2)$ & 0 & 89 \\
\hline Education P2 & $4(0.4)$ & $3(0.3)$ & $3(0.3)$ & $5(0.6)$ & 15 \\
\hline $\begin{array}{l}\text { Nursing management and } \\
\text { leadership P1 }\end{array}$ & $15(0.8)$ & $15(0.8)$ & $12(0.6)$ & 0 & 42 \\
\hline $\begin{array}{l}\text { Nursing management and } \\
\text { leadership P2 }\end{array}$ & $7(0.8)$ & $3(0.3)$ & $1(0.1)$ & $7(0.8)$ & 18 \\
\hline Total & 337 & 204 & 109 & 44 & \\
\hline
\end{tabular}

\section{Discussion}

During the 30-year period of the study, the topics of master's theses in the Department of Nursing Science were quite diverse, ranging from basic theoretical and methodological work to a wide range of topics in education, leadership and clinical research. At first glance, it is difficult to detect any trace of systematic cumulative knowledge building. The students enter the master's programme bringing with them some experiences and concerns from their clinical practice about which they want to gain more knowledge. This may help to explain the diversity of topics. Our findings show that choice of topics from clinical practice was related to patient issues as well as professional work-related issues. Analysing the findings in more depth, we find that nurse students have been engaged with some basic nursing phenomena throughout the 30 years. They have investigated how patients experience being patients and their experiences of their illness, by using patients and their relatives as respondents. Studies dealing with being a receiver of care increased from P1 to P2. An important question is: Why do master's students address the same nursing phenomena throughout all the years? We would argue that addressing the same phenomena is in fact not a matter of repetition. The findings must be considered and understood in light of the great changes the health care system has undergone throughout these 30 years. Both being a receiver of care and nurses' deliberations and enactments take place in very different contexts today than in the past health care system. Previously, patients were hospitalised for much longer periods than today. Currently, patients are discharged from hospital earlier than just a few years ago and caring for many of these patients has been transferred from hospitals to community-based services. This trend is taking place both internationally ${ }^{[3]}$ and at national level. ${ }^{[15]}$ In Norway, reforms and white papers from the Government have emphasised that caring for patients in their homes is the desired policy. ${ }^{[16,17]}$ Home care services became a part of public health care services as early as in $1972,{ }^{[18]}$ but from 1984 they were under local authorities. ${ }^{[19]}$ From the early start of providing these services in the community until today, the complexity of patients' health care needs have changed, 
which also affects requirements of competencies and new knowledge about patients and practice. We identified an increased number of theses on community care from 2005 onwards. However, there is still limited knowledge of the requirements for good-quality home care. ${ }^{[20]}$ Future research into master's theses should address this.

Another challenge which occurs when patients are discharged earlier and sicker than before is the increased need for collaboration and coordination between the two sectors of specialist and community care. These changes have brought invisible cultural diversities between the two sectors to the surface because community care services have mainly been concerned with long-term care while hospital nurses mainly held an acute care perspective on their patients. ${ }^{[21]}$ One implication is insufficient exchange of information when patients are discharged from hospital. ${ }^{[22]}$ Some of the master's theses from P2 elaborated on these challenges and pointed out that nurses in the two service levels have limited knowledge about each other.

Nurses' responsibility for providing high-quality and safe care as a fundamental nursing issue can be traced from Florence Nightingale until today. Allen ${ }^{[23]}$ has revealed that nurses have a significant role in ensuring safe patient care throughout patient trajectories. When the conditions for caring change, the analysis of master's theses shows that nurses want to investigate the consequences for patient care. Salmond and colleagues point out driving forces for transformative changes that force nurses to emphasise the implications for patients, practice and education. ${ }^{[1,24]}$ Nurses' education has been designed to meet a societal need. ${ }^{[1]}$ For the future, the driving forces of accountability and technology have implications for the "complex processes that make up the broad spectrum of care" [1] (p. 328) and the movement towards inter-professional teams where nurses play an important role. These forces call for the (re)design of health care and the education system needs to train skilled clinical nurses positioned to meet the new demands. This is likely to be reflected in future master's theses. We identified that some of the students were concerned with nurses' role and position in inter-disciplinary teams. But we expect more students to elaborate on this in the future.

The number of master's theses addressing education has slightly decreased. One significant external issue that may have influenced the chosen topics is the changes in the educational system in Norway. In 1981, all nursing schools were transferred to the university college level of education. The authorities required master's level qualifications. The Department of Nursing Science then provided a master's programme for this purpose. Although the Department initially educated teachers and nurse leaders until 2005, the majority of the theses were related to aspects of patient studies. During the 30 years, a steady decrease of theses related to nursing education and management was observed. Several students chose our master's programme because they had in mind positions in education or leadership after graduating. Therefore, it is puzzling to understand why so few of them addressed issues related to education and leadership issues in their theses.

Throughout the entire period, only $8 \%$ of the studies focused on nursing management and leadership. This is to some extent a surprising finding considering the great changes the health care system has undergone. For the last 15 years, huge changes in hospital leadership have taken place. ${ }^{[25,26]}$ One of the master's theses identified that one of the national nurse pioneers, Ingrid Wyller, argued for the importance of having nurse managers on the administrative board where all decisions were made as early as in 1952. But from the fifties until today, much negotiation and debate have taken place. Previously all hospitals had chief nurses, but after a hospital reform in the mid-1990s, these positions were mostly discontinued and neutral leadership models were introduced. Taking these dramatic changes into consideration, we would have expected leadership to be highlighted more in the theses, especially in view of the aforementioned drivers for future challenges and changes. Gerard et al. ${ }^{[1]}$ point out the need for preparing nurses for leadership and becoming change agents. This is not greatly reflected in our material. These findings should be used for further reflection for educational purposes as well as for research.

Throughout the entire period, we identified that the majority of students applied qualitative approaches. This is interesting from the perspective that qualitative approaches to a certain extent are regarded as important to understand the nature and phenomena of a profession. ${ }^{[27]}$ The fact that most studies focused on the experiences of patients and relatives may explain why the majority of students used a qualitative approach in their master's thesis. Qualitative studies are well suited for this purpose. On the other hand, external drivers today are expectations of intervention studies and the use of mixed methods in nursing science. ${ }^{[28]}$ One reason for identifying very few experimental and intervention studies may be explained by the length of the study programme, especially when it decreased from three to two years of full-time study. In line with Dobratz et al., ${ }^{[6,29]}$ we also found, in particular during P1, that many students used literature studies.

This study has some limitations. We may have overlooked some master's theses because of wrong filing in the library. Also, some students' theses might have had restricted access 
in the university's open publishing channels because the students had in mind later publication. This applies particularly after 2005. This means that we did not have access to investigate these theses more in depth as we did with some of the material when we were unsure of what topic they belonged to. However, even in the case of restricted access, the abstract should be available electronically.

\section{Conclusion}

An educational institution, as a part of a society, must meet the requirements to educate nurses who are prepared to fulfil the profession's social mandate. Both external and internal factors govern students' freedom to choose a topic for their master's thesis.

The current analysis of master's theses is important as a historical framework to verify the research that has taken place and if the changing strategy is going in the desired direction. The analysis has provided us with a clear picture of the research carried out by master's students over a 30-year period. The analysis revealed that the topics reflected a variety of issues. The situation has changed in recent years, where politics, professionalism and programmes of research have become influential in guiding students to systematic knowledge development with an international perspective. Examination of research-based master's theses provides insight into the past and present and may help to reflect the extent to which the master's programmes are able to meet future trends. Health care will undergo transitions to increased individual accountability for the outcome of health care; new technology will be developed and the need for inter-disciplinary approaches will increase due to complexity in health care. We argue that future studies addressing these topics and their implication for nursing practice and education are highly needed. This study can be used by other graduate nursing programmes to examine the contribution of their master's theses to developing nursing science, the factors that influence such programmes, for comparison and the clinical relevance of the work.

\section{ACKNOWLEDGeMENTS}

We want to thank Ass. Professor Randi Nord for valuable input during the study and Researcher Linda Aasvangen for searching for literature and abstracts, and for organising the abstract and making them ready for analysis.

\section{CONFLicts OF INTEREST Disclosure}

No conflict of interest.

\section{REFERENCES}

[1] Gerard SO, Kazer MW, Babington L, et al. Past, present, and future trends of master's education in nursing. J Prof Nurs. 2014; 30(4): 326-32. PMid:25150418 https://doi .org/10.1016/j.profnu rs.2014.01.005

[2] Institute of Medicine Committee on the Robert Wood Johnson Foundation Initiative on the Future of Nursing The Future of Nursing: Leading Change, Advancing Health. Washington (DC): National Academies Press (US). National Academy of Sciences. 2011.

[3] European Commission. Long-term care in the European Union. Brussel: EU; 2008.

[4] de Gutierrez MG, Leite JL, Pagliuca LM, et al. Multiple issues researched and to research in nursing. Rev Bras Enferm. 2002; 55(5): 535-41.

[5] Leino-Kilpi H, Suominen T. Nursing research in Finland from 1958 to 1995. Image J Nurs Sch. 1998; 30(4): 363-7. https: //doi.org/10.1111/j.1547-5069.1998.tb01334.x

[6] Dobratz MC, Primomo J, Delo D. A comparative analysis of master of nursing students' scholarly inquiry. J Prof Nurs. 2012; 28(6): 369-76. PMid:23158200 https://doi.org/10.1016/j.profnu rs.2012.04.014

[7] Lenz ER, Hardin SB. The Nursing Profession. Tomorrow and Beyond: Sage Publications, Inc.; 2001.

[8] Donaldson SK, Crowley D. The Dicipline of Nursing. Nursing Outlook. 1978; 26(2): 113-20. PMid:245616

[9] WHO. Verdens sundhedsorganisations ekspertkomite om sygepleje. Femte rapport. Københanvn. 1967.

[10] Nursing Research. Report and recommendations. 1996.
[11] Kunnskapsdepartementet. Frihet med ansvar — Om høgre utdanning og forskning i Norge. 2000.

[12] Tjora AH. Kvalitative forskningsmetoder i praksis. 2ed. Oslo: Gyldendal Akademisk; 2012.

[13] Kim HS. The nature of theoretical thinking in nursing. 3rd ed. ed. New York: Springer; 2010.

[14] Hsieh HF, Shannon SE. Three approaches to qualitative content analysis. Qual Health Res. 2005; 15(9): 1277-88. PMid:16204405 https://doi.org/10.1177/1049732305276687

[15] Helse- og omsorgsdepartementet. Morgendagens omsorg. Oslo; 2013.

[16] Helse- og omsorgsdepartementet. Samhandlingsreformen. Rett behandling - på rett sted - til rett tid. 2009.

[17] Helse- og omsorgdepartementet. Fremtidens primærhelsetjeneste nærhet og helhet. 2014-2015.

[18] Holm SG, Mathisen TA, Sæterstrand TM, et al. Allocation of home care services by municipalities in Norway: a document analysis. BMC Health Services Research. 2017; 17(1): 673. PMid:28938892 https://doi.org/10.1186/s12913-017-2623-3

[19] Grund J. Helsepolitikk i 1990 årene. Effektivisering, spill eller utvikling. Oslo: TANO; 1991. $305 \mathrm{p}$

[20] Bjornsdottir K, Ceci C, Purkis ME. The 'right' place to care for older people: home or institution? Nurs Inq. 2015; 22(1): 64-73. PMid:23786552 https://doi.org/10.1111/nin.12041

[21] Hellesø R, Fagermoen MS. Cultural diversity between hospital and community nurses: implications for continuity of care. Int J Integr Care. 2010; 10: e036. PMid:20422021 
[22] Helles $\emptyset$ R, Melby L, Brattheim B, et al. Exchange of Information Between Hospital and Home Health Care: A Longitudinal Perspective. Stud Health Technol Inform. 2016; 225: 349-53.

[23] Allen D. The Invisible Work of Nurses. Hospitals, organisation and healthcare. Abingdon, Oxon: Routledge; 2015. 153 p.

[24] Salmond SW, Echevarria M. Healthcare Transformation and Changing Roles for Nursing. Orthop Nurs. 2017; 36(1): 12-25. PMid:28107295 https://doi.org/10.1097/NOR. 0000000000 000308

[25] Kjekshus LE, Harsvik T. [Development of organizations in Norwegian hospitals]. Tidsskr Nor Laegeforen. 2007; 127(3): 288-90. PMid:17279106
[26] Spehar I, Frich JC, Kjekshus LE. Professional identity and role transitions in clinical managers. Journal of Health Organization and Management. 2015; 29(3): 353-66. PMid:25970529 https: //doi.org/10.1108/JHOM-03-2013-0047

[27] Patton QM. Qualitative Research \& Evaluation Methods. 3ed. Thousand Oaks, California: Sage Publications; 2002.

[28] Richards DA. The complex intervention framework. In: Richards DA, Hallberg IR, editors. Complex Intervention in Health Care. London: Routledge; 2015. 1-15 p.

[29] Dobratz MC, Primomo J, Bjorling E. Outcomes of scholarly inquiry: an analysis of Master's of Nursing students' projects/theses. J Prof Nurs. 2006; 22(5): 296-303. PMid:16990121 https://doi.org/ $10.1016 / j$.profnurs .2006 .07 .010 